\title{
sciendo
}

DOI: 10.2478/jolace-2021-0016

\section{Blessing and curse of crowdsourcing among educational experts - a study of teachers' willingness to contribute as a crowd}

\author{
Rina Zviel Girshin ${ }^{1}$ \& Elżbieta Gajek ${ }^{2}$ \\ ${ }^{1}$ Ruppin Academic Center, Israel \\ 2 University of Warsaw, Poland \\ rinazg@ruppin.ac.il, e.gajek@uw.edu.pl
}

\begin{abstract}
Crowdsourcing is a new technique of gathering data or performing large scale tasks by outsourcing it to a wider public. Its role and potential in language education is investigated in first in its volume research enetCollect (European Network for the Combination of Language Learning and Crowdsourcing Techniques) COST project. This paper presents the most pertinent data about highly successful crowdsourcing portals for language learning, some educational projects based on teacher's contributions and analysis of a survey as a crowdsourcing activity. The paper analyses two surveys: a low response rate, large scale pan-European survey wherein a sample of language teachers od all station all over Europe was asked to answer some crowdsourcing related questions (Arhar Holdt et al., 2020) and a high response rate, small scale, survey among the distributors of the first survey in which they were asked to analyse the numbers and techniques they used to reach the crowd. The focus of this article is on an extension study to the teacher survey in which thousands of teachers were approached but the response rate was relatively low. While such low response data in other cases would have been perceived as a drawback and are rarely analyzed, in the context of crowdsourcing meta research this could be a goldmine of importance. The article demonstrates how educators mayor may not be willing to participate in a crowdsourcing activity.
\end{abstract}

Key words: crowdsourcing, language learning, survey, participation in crowdsourcing

\section{Introduction}

One of the more interesting questions of crowdsourcing is how we can reach the crowd and even more importantly how we can reach the crowd of experts? One of the approaches is to send online surveys or online activities to a crowd of experts. However afterwards the researcher could be confronted with a silent crowd that does not want to participate and contribute. The present study analyzes this vital aspect using unusually large survey of especially crowdsourcing prone population of ESL teachers all over Europe. The enetCollect (European Network for the Combination of Language Learning and Crowdsourcing Techniques) is an action C16105 funded by the COST (European Cooperation in Science and Technology). Within the action program many aspects were researched for several years. Themes such as the arising opportunities facing the integration of crowdsourcing techniques (Brabham, 2008) into learning environments as well as the blending of learning content with gamification and data harvesting (Lyding, Nicolas, Bédi \& Fort, 2018) were investigated. One of the crucial issues is the willingness to participate in the crowdsourcing activities.

There exists a consensus that it is a good idea to use a crowd of experts in creation, correction, filtering or any other analysis of educational or language learning materials (Estellés-Arolas \& González-Ladrón-de-Guevara, 2012). However, before using crowdsourcing 
techniques in creating language learning materials willingness of the crowd should be measured. And yet, surprisingly, no sound survey to establish the hard facts is to be found. That is why after years of academic cooperation in laying the theoretical framework, our multidisciplinary pan-European group of enetCollect researchers have conducted a unique in its scope survey in which a group of language teachers was asked to answer some crowdsourcing related questions (Arhar Holdt et al., 2020) and later a group of survey distributors was asked to analyse the numbers and techniques they used to reach the crowd.

Before presenting some of the results of this study let us address the scale of participation in crowdsourcing activities. Crowdsourcing consists of outsourcing a task to a wider public through an open call - dates to long before that date. The term crowdsourcing was first coined in 2006 in Wired Magazine by Jeff Howe. Crowdsourcing in education defined as "a type of an (online) activity in which an educator or an educational organization proposes to a group of individuals via a flexible open call to directly help learning or teaching" (Jiang, Benatallah and Schlagwein, 2018).

Both theory and practice teach us that crowdsourcing in education, if used correctly, can bring a great benefit and enrich educational content, stimulate creating a new data and new knowledge (metadata), provide practical experience and encourage innovation and creation of new environments. Crowdsourcing in education has a great potential and will be widely used.

In the next section of this article we will give some examples of successful crowdsourcing portals, then we will address survey as a crowdsourcing activity. Then we will present our study and its results, and at the last section we will present conclusions and propose some recommendation for researchers and creators of crowdsourcing portals for education.

\section{Crowdsourcing educational portals for language learning}

It is very important to be aware of real-life state of the art around crowdsourcing. It is paradoxical to a high degree. On the one hand we hear about it every day. From every pulpit we hear preachers of big data and crowd wisdom explaining to us its importance and high potential. Governments invest in it. Numerous applications promise us huge advantages through using it. On the other hand. we see extremely low impact of all those initiatives. When all is said and done, they can't break out of their niche. And yet inside the niche there are great successes. So how does it look really?

There are many portals for language learning based on crowdsourcing which gather huge multilingual audiences. Although it is not the place for a detailed presentation of any of them, some data provide insights into the scale of the crowd they reached in 2017-2018 (Gorovaia, Forascu 2019). Busuu which started in 2008 reached the audience of 70,000,000. Mango languages, launched in 2007, addressed 300,000 users. Duolingo reached 300,000,000 users starting in 2011. Babbel, opened in 2007, gathered 20,000,000 users. Rosetta Stone - the oldest in the set, founded in 1992, addressed 75,720,00 users. LiveMocha started in 2007, it attracted $12,000,000$ in its final year 2016. Elsa, started in 2015, attracted 2,000,000 users. Kahoot founded in 2012, attracted 70,000,000 unique users in 2018. All of them are examples of educational business entities. It means that educational business units are able to attract users as the content may facilitate and improve teaching. However, storing own materials in such portals can be risky. Teachers may intuitively feel afraid of a situation like what millions of educators experienced with WikiSpaces opened in 2005 and suddenly closed in 2018. The founders initially offered a good educational tool declaring support for teachers and students, 
explicitly explaining their ethical principles, but they abandoned their declarations giving the millions of users just two weeks for taking back their materials (Chua \& Rayner, 2019).

The data from the teachers' survey presented by Arhar Holdt et al. (2020) strongly confirmed that teachers used with their learners the tools focusing on content such as: using Duolingo (19\%), contributing to Wikipedia (19\%). They also confirmed their focus on content indicating the need for pre-prepared lesson plans, specific activities motivating learners to learn. They also indicated their own activities such as sharing teaching materials (77\%), using Duolingo (18\%). In the teachers' survey 924 of the respondents confirmed their willingness to prepare teaching materials, but this makes $81.8 \%$ of these who responded and only $52.8 \%$ of those who approached the survey.

All in all, such portals respond to the basic needs of their users - they provide opportunities for language learning and teaching in an easy way. Thus, many of them offer teachers functionalities which help them to invite entire classes. The immediate gains for learners are obvious and the language learned is ready to use in real-life communication or language classes. Also the gains for teachers are approachable, the teachers get a technique which allows for a methodological variety in class. The huge number of users of the portals for language learning illustrates the interest in their content. As many of them - Busuu, Duolingo, Kahoot offer specific functionalities for teachers who serve as enablers. The use of the portals add variety to their teaching techniques motivating learners to learn. Even if the service such as Memrise does not address their courses to teachers, it can be utilized by teachers as a complementary tool for learning to extend vocabulary, lexical patterns and collocations. For example, Łuczak (2015: 56-59) applied Memrise in her legal English courses. Her results showed that the students who used Memrise got better results than those who did not.

Such immediate incentives are not achievable in the case of participation in a survey as a crowdsourcing activity. The willingness to contribute to use content related crowdsourcing portals is mainly driven by professional aims such as professional development, enlarging teaching techniques. In the teacher's survey factors which may encourage them to participate in crowdsourcing activities involve acquiring new skills and knowledge, saving time on class preparation, gaining results that are valid for teaching, sense of contribution, peer support and team building, professional accreditation, financial compensation (Arhar Holdt et al., 2020).

\section{Survey as a crowdsourcing activity}

Collecting data via a survey as a tool is a crowdsourcing activity but it differs significantly from a content related crowdsourcing activity. Mainly in terms of gains. Willingness (or lack of it) to participate in a survey cannot be extrapolated on teacher's willingness (or lack of it) to participate in a language learning/teaching crowdsourcing activities as driving factors are different.

Web surveys have become widely used recently in many areas of social studies from marketing, politics to tertiary education. In our increasingly globalized world, cross-national research and thus cross-national datasets have grown in popularity in academic research. Thus, the potential respondents experience survey fatigue as they are asked to participate in many of them. The over-surveying results in a decrease of response rate (Mol, 2017). Web surveys have a potential to substantially increase sample sizes at minimal costs however typically achieve lower response rates from participants compared to more conventional survey methods (Sammut, Griscti, \& Norman, 2021). Marketing companies recruit panels of respondents to obtain survey results on a large scale. However, ComScore Networks reports 
that in $200530 \%$ of all online surveys were completed by only $0.25 \%$ of the internet population. Thus, broadening a respondent base is also a serious problem for professional marketing studies (Brüggen et al., 2011). They widely use financial incentives and flattery. Some researchers indicate the importance of familiarity of content by the respondents. The less familiar they are the less willingly they participate in the survey (Babbie, 2012). Others claim that country-specific factors such as the political and demographic, economic, and technological factors as well as the socio-cultural environment may have an effect on the response rates to web surveys (Daikeler, Silber, \& Bošnjak, 2021).

The study presented in this paper uses two different online surveys. First one, a large-scale teachers survey (TS), where language teachers were asked to answer how familiar they are with the concept of crowdsourcing and to addresses their attitude towards including crowdsourcing into language teaching activities. The detailed results of the survey are published (Arhar Holdt et al., 2020). This large-scale survey for teachers was administrated via an online questionnaire and collected volunteers' data on three major parts: (a) teachers' experience with organizing crowdsourcing activities for students/pupils, (b) the development of crowdsourced resources and materials as well as (c) teachers' motivation for participating in or employing crowdsourcing activities. Considering a survey as a crowdsourcing activity the second survey was designed to investigate the willingness of the professionals in education to contribute to such activity. The second survey, a small-scale one, where a group of representatives from different countries were given a task to analyse the methods of collecting data in the previous survey and the number of teachers approached and the response rate achieved.

\section{Study}

As mentioned before this study is based on two sets of data. The first set contains the results of a teacher survey (TS) to which both authors contributed at every stage of its development. The second set (referred further as MCMS) consists of a follow up survey applied to identify the background context of the TS for better understanding its implications for the use of crowdsourcing in language learning. The aim of this study is to analyze the willingness of the crowd of experts to share their knowledge. The study uses the results of the teacher survey in the light of the number of teachers approached and methods of approaching. The participants of the second survey were enetCollect Management Committee members (MCM), who were responsible for distributing the teachers survey in their countries. Those MCM, who were responsible for gathering data in their countries, were asked to answer a short questionnaire about the number of teachers approached, how and where they approached them and suggestions for the methods to obtain the higher participation of teachers.

Our study aimed to test in practice the following important research hypotheses:

H1. The educational experts, namely the teachers, willingness to share their knowledge in the form of a survey for free is lesser than expected.

H2. The MCM will be more willing to participate in online survey for free, will have a higher participation rate and will be glad to share their results.

$\mathrm{H} 3$. The MCM will be willing to analyze the effectiveness of the dissemination activities they applied in their countries and will supply critical commentaries and suggestions about how to reach more teachers, how to obtain the higher participation rate.

\subsection{Methodology and results}


In the TS 16241 participants entered the intro of the questionnaire but only 1750 proceeded and started responding (Arhar Holdt, 2018). The huge drop out in the interest of respondents-to-be just after the first contact with the survey requires further elaboration as only $10.8 \%$ of them decided to continue responding. Finally, only 1129 completed the survey as the number of responses dropped gradually with every question (Arhar Holdt, 2018). This makes the response rate of $6.9 \%$ among the ones who started answering. The possible interpretation of this fact will be discussed later in the text. This data supports our first hypothesis.

In the second survey, called MCMS, 18 MCM (out of 36) filled in the questionnaire containing mainly open questions about numbers of teachers approached, methods used to approach them and future suggestions about how to encourage the crowd of teachers to participate in survey activities. The coding for MCMs is used to protect their identity. This also means that the MCMs are not matched with the countries they represent. The response rate of $50 \%$ needs to be estimated as very high. It will also be discussed later in the text. This high response rate supports our second hypothesis.

The next paragraph supports our third hypothesis about willingness to analyze the effectiveness of the dissemination. The MCMs invested much time and thought into analyzing the different approach methods to respondents and analyzing them. The results are that the inquirers used several different methods of approaching teachers and encourage them to answer the survey questions. Some of the popular methods of approaching teachers included:

- personal contact with the colleagues,

- publishing posts in professional and institutional forums,

- sending an explanatory message and the survey link via mailing lists

Table 1 presents the results of analysis of various approach methods. We can see that there is a clear hierarchy with very different effectiveness of the method used to introduce the questionnaire to potential respondent. No special country-specific factors were found in those methods.

\begin{tabular}{|c|c|c|}
\hline method & $\begin{array}{c}\text { number of MCMs } \\
\text { who used it }\end{array}$ & $\begin{array}{c}\text { percentage of MCMs } \\
\text { who used it }\end{array}$ \\
\hline personal contacts with colleagues & 18 & 100 \\
\hline posts in online professional forums & 11 & 61 \\
\hline posts in social media professional groups & 11 & 44 \\
\hline usage of professional mailing lists & 8 & 33 \\
\hline $\begin{array}{c}\text { sending letters to high schools, language } \\
\text { schools and universities, teachers' }\end{array}$ & 6 & 22 \\
\hline associations & 4 & \\
\hline posts in institutional forum or webpage & & \\
\hline
\end{tabular}

Tab. 1: Methods of approaching respondents (by efficacy). 
The effectiveness of the MCM personal contacts indicated in the MCMs reveals the following findings:

- 16 MCM expressed their belief in personal contacts, however data show that they were not as effective as expected. They were aware of a limited number of responses obtained ( 7 MCMs out of 18). The rest was not able to provide any resulting numbers.

- 7 MCMs personally contacted their co-workers but the effectiveness of such contacts was either law or not possible to estimate (MCM1 3 contacts - all 3 shared and answered, 116 student teachers contacted - no data about answers, MCM4 out of 15 personally contacted only 4 answered, MCM7 out of 20 personally contacted no data about answers, MCM8 out of 5 personally contacted only 1 answered, MCM12 20 contacts they filled it in - 20 answers - and distributed the survey among their personal contacts no data about answers, MCM13 15 contacts answered and shared - no data about answers, MCM17 20 contacts - no data about answers). In total 93 respondents-to-be were contacted personally by MCMs, as stated above, plus 116 student teachers approached. However, the majority of the MCMs were not able to provide data about the effectiveness of such contacts.

The institutional contacts indicated in the MCMs as means of disseminating the survey among teachers. There are only 3 MCMs who knew the number of the recipients of their institutional mailing lists (MCM9 approached 75000 members of the ministry of education mailing list. MCM11 informed 1000 members of the institutional mailing list, sent mails to primary and secondary schools. MCM14 sent mails to 50 schools). The other 6 of the MCMs: (MCM3, MCM12, MCM14, MCM15, MCM16, MCM17) who used this channel of communication sent letters to high schools, language schools and universities, teachers' associations. One of them (MCM17) also contacted personally the Department Heads informing about the survey. All in all the data indicated by MCMs show 76000+ professionals approached. The fact that the MCMs are not aware of the number of recipients shows that the tools are used as a onedirectional way of communication between the institutions.

The effectiveness of the MCMs social media activities as indicated in the MCMS. The data is based on the number of users registered in social media groups:

- MCM1 28000 followers of three professional teacher's social media groups

- MCM2 5800 followers of two professional teacher's social media groups

- MCM5 3700 followers of the institution social media group

- MCM6 2100 followers of teachers' association social media group

- MCM11 3700 followers of three professional mailing lists

- MCM14 1300 followers of a teachers' social media group

All in all it makes $44600+$ followers of professional social media groups approached.

Although the number of respondents of the TS is known (ca 1750 teachers responded), the exact number of teachers approached is difficult to estimate as some MCMs were not aware of the number of members of a group or mailing list members or were not indicated the number of followers of a social media professional group they posted the information about the survey.

An estimation can be based on the known number of members of social media groups presented above. However, the question is to what extent the number of members of social media groups can be recognized as a number of teachers approached.

As our third hypothesis claims MCMs will supply critical commentaries about the teacher's survey and provide suggestions about how to reach more teachers. Indeed 12 MCMs provided some critical commentaries and suggestions. MCMs' suggested strategies for getting more replies from the crowd such as offering incentives such as teaching materials, appreciation, in 
return to the response; shortening the questionnaire; explaining the term crowdsourcing with examples (a brief definition of the crowdsourcing was given in the teachers survey); translating the questions into local languages; ensuring respondents that all answers are valid despite their previous experience or lack of it in crowdsourcing activities. Qualitative analysis of critical commentaries is listed below:

- $8 \mathrm{MCMs}$ raised the fact that the term crowdsourcing, especially crowdsourcing for language learning is not familiar to language teachers, could demotivate them to take part in the survey. Consequently, one MC noticed that because of such unfamiliarity they were not able to provide valid data showing their ignorance.

- 2 MCMs stated that the fact that teachers are not involved or even familiar with crowdsourcing hinder their participation as they could not figure out how their input could be useful.

- 4 MCMs raised the fact that the teachers get many questionnaires to fill in so they perceived questionnaires as time consuming tasks and as a result they were fed-up with them.

- 3 MCMs proposed to translate or partially translate the survey into teachers' mother tongue.

- 2 MCMs emphasised the excessive length of the survey and complexity of the questions as demotivators.

\subsection{Discussion of the results}

It is worth noting that in the open questions in the TS 18 respondents complemented the study expressing encouragements, e.g. "I really like the idea behind this survey. Well prepared and organized. Good luck with your study." which makes $1.6 \%$ of the respondents. However, the reasons behind the decision to abandon participation in the study at the initial stage of approaching it, were not revealed by the teachers. They may be inferred based on the MCMs answers as teachers are afraid of being perceived as ignorant (MCM17). To explain the unknown teacher's reluctance to answer, other studies and analyses that categorise teachers' attitudes to technology and novelty can be used such as: teachers' lack of computer literacy, teachers' resistance to novelty and unwillingness to change teaching habits (cf. Gajek, Zdravkova, 2020). On the one hand, teachers admit that their computer literacy is not adequate for effective teaching (cf. TALIS report 2018, 2019). On the other hand, teachers overestimate their digital competence (Maderick, Zhang, Hartley \& Marchand, 2016). Teachers prefer keeping working habits unchanged (Hiver \& Dörnyei, 2017) and refusing to adopt new learning (Powell \& Kusuma-Powell, 2015). Additionally, in the TS some voices expressed the usual reasons teachers raise that is lack of time and funds, lack of training, excessive work (Arhar Holdt et al., 2020).

One of the assumptions was that MCMs are willing to contribute and share their results and their response rate will be a high response rate. And indeed, MCMs response rate reached a very high response rate of $50 \%$. A survey response rate of $50 \%$ or higher is considered as excellent in most circumstances which supports our second hypothesis. A high response rate is likely driven by high levels of willingness to complete the survey, or a strong personal relationship between the survey topic and the respondent's interests and beliefs. The MCMs can be defined as "willing" participants of the experiment. They might receive peer-recognition in form of showing the other enetCollect members their role in survey, collaboration and ability to be a good team-member, getting professional benefits in form of publicity or publication, mentioning their own name and their country in the list of participants, and many 
others. As the MCMs collaborate within the project activities, all of them are experienced researchers and data collectors, they had put a lot of effort to attract the teachers and gain the results, they wanted to:

- understand the reasons of lack of effectiveness,

- compare the strategies in the dissemination of the survey,

- explain the factors contributing to the final results,

- draw the conclusions which allow for further development of the project,

- infer the factors which may enhance contribution to crowdsourcing activities.

\section{Conclusion}

The follow-up survey study (MSMS) allows for the estimation of a very low response rate among teachers. Such data, crucial for introducing crowdsourcing activities among educators, is rarely published. However, it provides insights into teachers' preferences towards crowdsourcing activities. On the one hand, teachers are keen on using popular portals to vary their teaching methods, which provide them with clear professional gains. On the other hand, a survey seems to be the least attractive crowdsourcing activity as it requires effort, time but it does not bring immediate benefits, either extrinsic or intrinsic. Thus, participation without immediate gains may be perceived as being used and contribute to the decision whether to participate. Even using creative multiple means of dissemination of the survey such as authorities channels, personal bonds, institutional mailing lists and social media did not bring the estimated results among teachers. The results confirmed by the MCMs illustrate the experiences gathered earlier among students and in business context. Over surveying and unwillingness to share information also affect, to a great extent, professionals in education.

Educational experts need stronger and specific incentives to be willing to participate in the survey e.g. credits as for student teachers, authority obligations e.g. Ministry requirements etc. The results confirm that a survey per se as a crowdsourcing activity is not engaging enough for experts to participate. It also shows that participation in a crowdsourcing activity is content driven and rewards and gains driven. Thus, more attention should be given to content and gains of experts relevant to their individual professional situations. We saw evidence for this conclusion in the high response rate achieved among participants of the second survey. Looking towards the future and further studies on crowdsourcing the authors are aware that the coronavirus (COVID-19) pandemic has revolutionized learning and teaching environment showing that some teachers and students are willing to move from traditional face-to-face instruction to distance learning formats through virtual classrooms. They may be more willing to open their classes to the use of crowdsourcing activities in their teaching from one side, but many professionals are worried that their recorded materials will be used against them. The new normal which will emerge in teaching and learning languages will also open a new area for studies on the role of crowdsourcing as a technology-related social practice in education.

All in all, our study shows various facets of problematics of crowdsourcing even of such an easy group as teachers and other educational experts as a crowd. Special attention should be paid to individual aspect of engagement in a crowdsourcing project. Even if a huge crowd of teachers - potential contributors or respondents - is approached, their active participation is neither guaranteed nor could be estimated at the high level.

This study has several limitations. One of the major limitations of teacher's online survey was that the population to which it was distributed cannot be described. Only teachers who finished the survey submitted their personal information as a last phase of the survey. 
Additional limitation is that the study was conducted in a self- selected sample of teachers who volunteered to answer the survey. Also, only European language learning teachers were approached. One of the limitations of the second follow-up survey study of distributors of the teacher's survey is that the analysis of the effectiveness of the dissemination activities was done using estimation based on the numbers known to Management Committee members. Additional limitation is a small number of the participants, as only 50 percent of the MC members responded.

\section{Acknowledgments}

The authors are grateful to the collaborators, especially to all MCMs who answered the questions we send them and to co-designers of the teachers' survey and co-authors of the article analysing the teachers' data. The authors extremely grateful to enetCollect CA16105 COST action for supporting this research and the funding opportunity for it.

\section{References}

Arhar Holdt, Š., Zviel-Girshin, R., Gajek, E., Durán-Muñoz, I., Bago, P., Fort, K., Hatipoglu, C., Kasperavičienė, R., Koeva, S., Lazić Konjik, I., Miloshevska, L., Ordulj, A., Rodosthenous, Ch., Volodina, E., Weber, T. \& Zanasi, L. (2020). Language teachers and crowdsourcing: Insights from a cross-European survey. Rasprave: Časopis Instituta za hrvatski jezik i jezikoslovlje, 46(1), 1-28, https://doi.org/10.31724/rihjj.46.1.1.

Arhar Holdt, S. (2018). Teachers and Crowdsourcing Survey Results. COST Wnet-Collect WG1 Meeting, Gothenburg, 6.12.2018.

Babbie, E. R. (2011). The Practice of Social Research, Thirteenth edition. Boston, MA. Cengage Learning.

Brabham, D. C. (2008). Crowdsourcing as a model for problem solving: An introduction and cases. Convergence, 14(1), 75-90, https://doi.org/10.1177/1354856507084420.

Brüggen, E., Wetzels, M., de Ruyter, K., \& Schillewaert, N. (2011). Individual differences in motivation to participate in online panels: the effect on response rate and response quality perceptions. International Journal of Market Research. 53(3), 369-390, https://doi.org/10.2501/IJMR-53-3-369-390.

Chamberlain, J., Kruschwitz, U., \& Poesio, M. (2012). Motivations for participation in socially networked collective intelligence systems. Presented at Collective Intelligence conference, 2012 arXiv:1204.2991.

Chua, C., \& Rayner, M. (2019). What do the Founders of Online Communities Owe to their Users? CEUR workshop proceedings. Vol.2390. 55-60. http://ceur-ws.org/Vol2390/PaperD1.pdf.

Daikeler, J., Silber, H., \& Bošnjak, M. (2021). A Meta-Analysis of How Country-Level Factors Affect Web Survey Response Rates. International Journal of Market Research, https://doi.org/10.1177/14707853211050916.

Estellés-Arolas, E., \& González-Ladrón-de-Guevara, F. (2012). Towards an integrated crowdsourcing definition. Journal of Information science, 38(2), 189-200, DOI: $\underline{10.1177 / 0165551512437638}$ 
Gajek, E., \& Zdravkova, K (2020). Preparing teachers for crowdsourced language learning" to Infotheca. Journal for Digital Humanities 20(1-2), 7-26.

https://doi.org/10.18485/infotheca.2020.20.1_2.1

Gorovaia, N., \& Forascu, C. (2019). Configurational perspective on business models in language learning. Presentation at WG1 workshop: Crowdsourcing related to corpus examples for language learning University of Coimbra, Coimbra, Portugal, December 5-6, 2019.

Hiver, P., \& Dörnyei, Z. (2017). Language teacher immunity: A double-edged sword. Applied Linguistics 38(3), 405-423, https://doi.org/10.1093/applin/amv034.

Howe, J. (2006) The rise of crowdsourcing. Wired magazine 14(6), 1-4, http://www. wired. com/wired/archive/14.06/crowds.html.

Jiang, Y., Schlagwein, D., \& Benatallah, B. (2018, June). A Review on Crowdsourcing for Education: State of the Art of Literature and Practice. In PACIS (p. 180), https://aisel.aisnet.org/pacis2018/180.

Lyding, V., Nicolas, L., Bédi, B., \& Fort, K. (2018). Future-proof CALL: language learning as exploration and encounters-short papers from EUROCALL 2018, 176, https://doi.org/10.14705/rpnet.2018.26.833.

Łuczak, A. (2015). “Memrise w nauce języka prawniczego” In: E.Gajek (ed.) Technologie mobilne w kształceniu językowym, (pp. 49-63). Warszawa: Texter.

Maderick, J. A., Shaoan, Z., Hartley, K., \& Marchand, G. (2016). Preservice teachers and selfassessing digital competence. Journal of Educational Computing Research 54(3), 326-351, https://doi.org/10.1177/0735633115620432.

Mol Van, Ch. (2017). Improving web survey efficiency: the impact of an extra reminder and reminder content on web survey response. International Journal of Social Research Methodology, 20(4), 317-37, https://doi.org/10.1080/13645579.2016.1185255.

Powell, W., \& Kusuma-Powell, O. (2015). Overcoming resistance to new ideas. Phi Delta Kappan International. 96(8) 66-69 DOI: https://doi.org/10.1177/0031721715583967

Sammut, R., Griscti, O., \& Norman, I. J. (2021). Strategies to improve response rates to web surveys: a literature review. International Journal of Nursing Studies, 123, 104058.

TALIS teacher guide to TALIS 2018, http://www.oecd.org/education/talis/TALIS-TeachersGuide-to-TALIS-2018-Vol-I ENG.pdf

TALIS 2018 Results (Volume I) Teachers and School Leaders as Lifelong Learners (2019) https://read.oecd-ilibrary.org/education/talis-2018-results-volume-i 1d0bc92aen\#page1

\section{Contact}

Elżbieta Gajek PhD hab.

Institute of Applied Linguistics, University of Warsaw

00-312 Warsaw, Poland

https://orcid.org/0000-0003-2971-8334

e.gajek@uw.edu.pl 


\section{Rina Zviel Girshin PhD}

Faculty of Engineering,

Ruppin Academic Center,

Emek Hefer

4025000 Israel

https://orcid.org/0000-0002-7926-4476 rinazg@ruppin.ac.il 